\title{
Accreditation: Application of Kurt Lewin's Theory on Private Health Care Organizationanl Change
}

\author{
Samia Saleem ${ }^{1 *}$, Sana Sehar ${ }^{2}$, Muhammad Afzal ${ }^{3}$, Awais Jamil ${ }^{4}$, Dr. Syed Amir Gilani ${ }^{5}$ \\ ${ }^{1}$ BSN (Student), Lahore School of Nursing, The University of Lahore, 1- Km Raiwind Rd, Sultan Town, Lahore, Punjab, Pakistan \\ ${ }^{2}$ Assistant Professor at LSN (UOL), Lahore School of Nursing, The University of Lahore, 1- Km Raiwind Rd, Sultan Town, Lahore, Punjab, Pakistan \\ ${ }^{3}$ Professor at LSN (UOL), Lahore School of Nursing, The University of Lahore, 1- Km Raiwind Rd, Sultan Town, Lahore, Punjab, Pakistan \\ ${ }^{4}$ Nursing Manager, Lahore School of Nursing, The University of Lahore, 1- Km Raiwind Rd, Sultan Town, Lahore, Punjab, Pakistan \\ ${ }^{5}$ Dean: Faculty of Allied Health Sciences, Lahore School of Nursing, The University of Lahore, 1- Km Raiwind Rd, Sultan Town, Lahore, Punjab, \\ Pakistan
}

$\begin{aligned} & \text { DOI: } 10.36348 / \text { sjnhc.2019.v02i12.003 } \\ & \text { *Corresponding author: Samia Saleem }\end{aligned}$
Abstract

An accreditation plan can improve an organizational facilities and services regarding patient care and provides quality improvement skills. In my case scenario, I conceptualized an idea about accreditation of private well-established health care setting. The Kurt Lewin's theory insights a framework of change at the accreditation level, which will be achieved by the application of the transformational leadership style. Transformational leadership style works as guider, motivator, collaborative and bind with sustain the change management mission. The accreditation requires an international standard of practices and high quality of patient care in an organization. The accreditation requirement is fulfilled in the context of organizational cultural and environmental values, beliefs and delivery of services. In the case scenario presented an idea by the reflection on its organizational change. The private health care organization had accreditation capabilities. All essential and standardized equipment and performing procedural guidelines and following protocols. Kurt Lewin's theory give directions to such these kind of organizations in the context of change at the level of accreditation.

Keywords: Health Care Organization, Accreditation, Kurt Lewin's Theory, Transformational Leader, Cause and Effects. Copyright @ 2019: This is an open-access article distributed under the terms of the Creative Commons Attribution license which permits unrestricted use, distribution, and reproduction in any medium for non-commercial use (NonCommercial, or CC-BY-NC) provided the original author and source are credited.

\section{INTRODUCTION}

The accreditation programs for healthcare providing organizations verify patient safety and quality of care and adopt these programs willingly for better chances of getting funding, better business opportunities and reputation as a certified healthcare facility. Joint Commission International (JCI) is considered as the leader in global healthcare with central objective to improve patient safety and quality of healthcare by work together with healthcare facilities and government organizations in more than 100 countries around the globe [1]. Accreditation provides the suitable and perfect means to building quality and enhance patient safety [2].

\section{CASE SCENARIO}

During the job period, I had work in a private health organization. That health organization was consisted well establish equipped, and great fall in developed organizations. That private organization had provided the quality of care, accomplishing the patient safety goals. Furthermore, following the ground roles of patient autonomy, ethical considerations, and gave respect their close relations about complete information in the respect of the journey of the patient's disease. Throughout that duration of my job, I was observed this organization want to take a step for accreditation. According this case identify, need to apply the change management theory of Kurt Lewin's.

\section{Rational}

An organized institute should have to prove their practices, and quality of work on the stage of world. Must get international accreditation, to enhance their power and expertise in the world.

\section{Change Management Process}

By following the health organizational change management process, worked through the Transformational Leadership style. Transformational leadership style focuses on four elements these elements are Independent and change management is dependent variable. 
1. Individualized Consideration is the extent to which the leader attends to each follower's needs and as a mentor, coach or guide to the followers.

2. Inspirational Motivation is the degree to which a leader articulates appealing vision that inspires and motivates others to perform beyond expectations.
3. Idealized Influence describes leader that are role models for their followers because they engage in high standards of ethical behavior.

4. Intellectual Stimulation is the extent to which the leaders challenge assumption take risk and solicit the ideas [3].

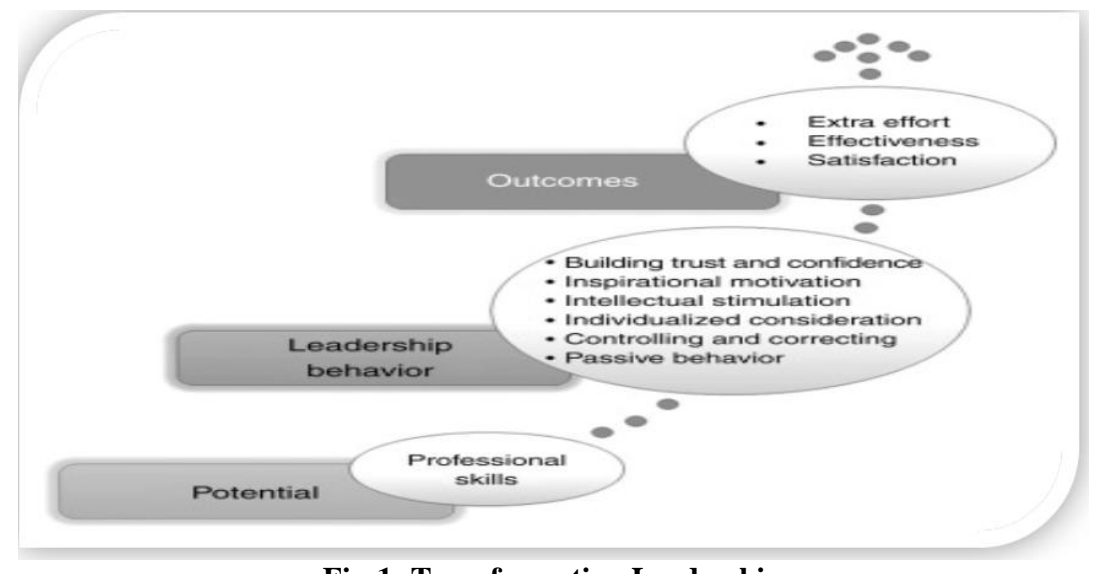

Fig-1: Transformation Leadership

\section{Change management theory application}

To application of Kurt Lewin's change management theory on private health care accreditation plan. Lewin's theory works on three steps.
2. Moving / change is implemented that expected change.

3. Refreezing step is ensuring that the change becomes permanent.

1. Unfreezing steps is ensuring that employees are ready for change.

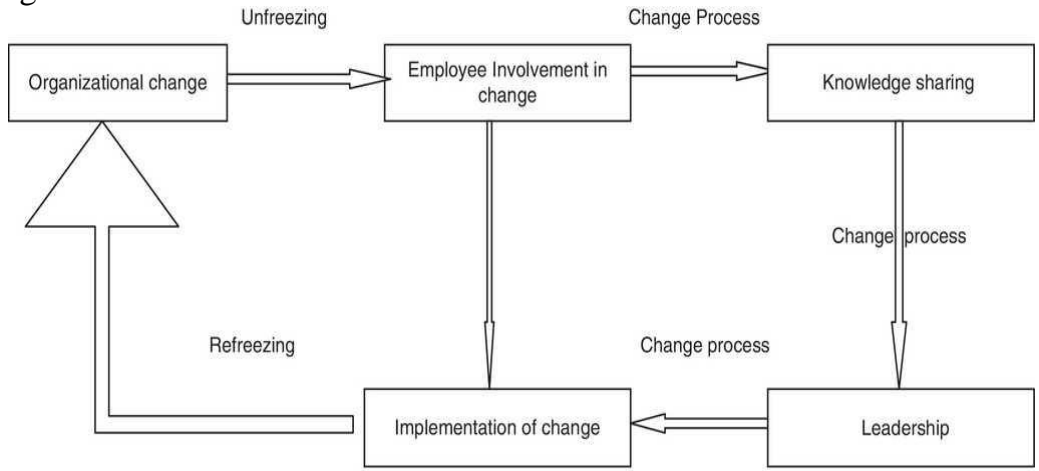

Fig-2: Organizational change process showing different stages

Following 3 steps of change theory transformational leadership plays a role as a change agent. This type of leader coordinates with employees and share their plans, give opportunity in making decisions in organizational change process [4].

Lewin's [5] suggests that to change management processes, an organization must 'unfreeze' its current state into a natural position so that old behavior can be unlearned and new behavior can be successfully adopted. Then change should be applying as driving force for and organizational change and minimizing the resisting forces. Once change take place, the organization will 'refreeze' in to the new state [6].

\section{Decision Making In Change Management Process}

On that point, if I participate in decision making, in health organizational change management process, to take a step for organizational involvement at administration level to follow the hierarchy and involve employee to participate in decision making process. Present the idea in front of them, make objectives and start work as transformational leader, and convince them to participate as team to achieve the accreditation award.

The process of change management works on following steps: visualize the change need, prepare for change, design the MAP for change, deploy, sustain the change in an organization after accreditation reward. 


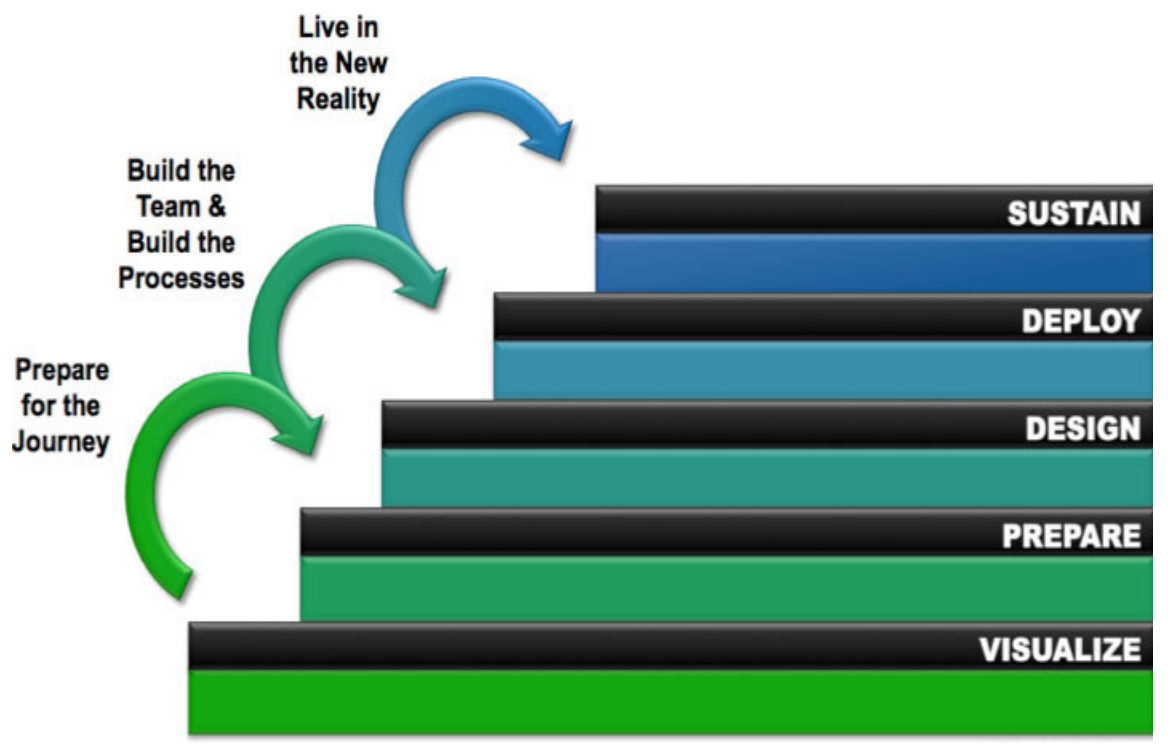

\section{DISCUSSION: (LITERATURE RESULTS)}

In the light of cause and effects results literature reviewed:

First of all, the main cause of accreditation for an organization had a great chance to prove their certified stability within country level. Including, the reason is to helps regulate if an institution

Secondly, it assists the organizations in determining acceptability of transfer credits. Furthermore, it helps employers determine the validity of programs of study and provide the research options. To creates goals for institutional self-improvement, provides a self-regulatory alternative sustain the organizational functions [7].

In decision, accreditation is expected to provide pathways to responsibility, reliability, and better fit between community needs and public health services. National strategies pointing rapid distribution of accreditation among public health agencies should include elements that address the needs of local health departments with fluctuating degrees of committed to trail accreditation.

Firstly, the impact of an organization change creates an opportunity for the development of best practices, leadership development and team development. The change is predictable and unavoidable. In this article they work on change management following the McKinsey's 7s Model. In this model of change management focus on two categories the soft and hard area. The hard areas consist of the system, strategy and structure while the soft system areas include skills, style, staff and shared values which normally are difficult to manage but considered as the foundations of the organization and are source of sustainable competitive advantage [8].
Secondly, an organization frequently face pressure for change, which are both internal and external in nature. External pressures include increasing globalization, communication tract, and political exposure. Meanwhile, internal pressure contributes in the staffing relation with change, budged, increasing level of education, and desire to better quality [9].

Thirdly, the effect on an organizational change reflects the accreditation process is largely viewed as a quality assurance process, which often feeds in to quality improvement activities if the feedback aligns with organizational priorities. Three key stages are required for accreditation to impact quality: coherence, organizational buy-in and organizational action. These stages map to constructs outlined in Normalization Process Theory.

Coherence is established when an organization and its staff perceive that accreditation aligns with the organization's beliefs, context and model of service delivery.

Organizational buy-in is established when there is both a conceptual title holder and an operational titleholder, and is influenced by both internal and external contextual factors. Quality improvement action occurs when organizations take purposeful action in response to observations, feedback or self-reflection resulting from the accreditation process [10].

Finally, Park, Jung, \& Suk [11] describes in their study, the health care accreditation had a great impact on an organizational effort and quality of work. This study works on following themes: including 1) Healthcare employee's perception on healthcare accreditation, 2) Impact of health care accreditation on quality of healthcare, 3) Patient safety and healthcare quality. 4) Satisfaction of healthcare employees, 5) Leadership, 6) Organizational culture, and 7) 
Managerial performance. The effects of accreditation on an organization provide an effective tract for improving the quality of health care.

According to Belawati, Setyadi, and Hendri [12] describes in their study, a transformational leadership has a great impact on organizational change process, on empowerment, on creativity of members, on leaning the organization certification, on an organizational innovation.

The principle of transformational leadership, that to be connected with, for positive organizational outcomes. It focuses on the process of building employee trustworthiness to meet the organizational vision, mission, strategies, objectives by the leader [13].

These efforts must be made an organization to reduce job stress and to formulate the rewarded strategies at national level [11]. More significantly, managing confrontation to change in an effective manner helped the organizations to deal smoothly the application of change [8].

Additionally, this certification program Involves staff, faculty, trainees, other paramedical staff, and management advisory team in organizational evaluation and planning [7].

\section{Limitation}

The limitation of this study is that the change theory is only used to analyze the phenomenon, but not be used as instructions in private organization accreditation.

\section{CONCLUSION}

This study paper will reflect the change management process. In this article paper present the change management theory application for accreditation plan in private health care organization, following the transformational leadership style. This style motivates the co-workers to participate in achieving the goal in formal and in the way of sustainable change. In the light of this literature reviews had reflected the most of respondents report a change in an organization very stressful.

Conflicts of Interest: No conflicts of interest declared by authors.

Financial Disclosure: The authors declared that no financial support received in this case study.

\section{REFERENCE}

1. Zaman, M. U., \& Fatima, N. (2015). Accreditation of Healthcare Facilities: A Friend or Foe?.

2. AbdelWareth, L. O., Pallinalakam, F., Ibrahim, F., Anderson, P., Liaqat, M., Palmer, B., ... \& Alduaij,
A. (2018). Fast track to accreditation: an implementation review of College of American Pathologists and International Organization for Standardization 15189 accreditation. Archives of pathology \& laboratory medicine, 142(9):10471053.

3. The qualities of transformational leaders and what distinguishes them from transactional leaders. $C Q$ Net, Retrieved at [October 26, 2019].

4. Hussain, S. T., Lei, S., Akram, T., Haider, M. J., Hussain, S. H., \& Ali, M. (2018). Kurt Lewin's change model: A critical review of the role of leadership and employee involvement in organizational change. Journal of Innovation \& Knowledge, 3(3), 123-127.

5. Lewin, K. (1947). Frontiers in group dynamics: II. Channels of group life; social planning and action research. Human relations, 1(2), 143-153.

6. Hossan, C. (2015). Applicability of Lewin's change management theory in Australian local government. International Journal of business and Management, 10(6):53.

7. The importance of Accreditation. (2015). PARALEGAL.EDU. Retrieved from [October 13, 2019]. https://www.paralegal.edu/blog/theimportance-of-accreditation

8. Jalagat, R. (2016). The Impact of Change and Change Management in Achieving Corporate Goals and Objectives: Organizational Perspective. International Journal of Science and Research (IJSR), 5:1233-1239.

9. Shivappa, R. (2015). Change Management Concept, Process, Principles and Skills. Retrieved on [October 12, 2019], from http://www.slideshare.net/shivapparamakrishna/ch ange -manage-dr-r-shivappa.

10. Desveaux, L., Mitchell, J. I., Shaw, J., \& Ivers, N. M. (2017). Understanding the impact of accreditation on quality in healthcare: A grounded theory approach. International Journal for Quality in Health Care, 29(7):941-947.

11. Park, I., Jung, Y., \& Suk, S. (2017). The perception of healthcare employees and the impact of healthcare accreditation on the quality of healthcare in Korea. Journal of Hospital Administration, 6(6):20-27.

12. Belawati, F. E., Setyadi, D., \& Hendri, M. I. (2019). Effect of Transformational Leadership Style and Knowledge Management on Organizational Innovation through Empowerment, Member Creativity and Learning Organization. Journal of Arts and Humanities, 8(8):1-16.

13. Wen, L., Yang, H., Bu, D., Diers, L., \& Wang, H. (2018). Public accounting vs private accounting, career choice of accounting students in China. Journal of Accounting in Emerging Economies, 8(1):124-140. 